\title{
Gender for Energy Technological Using in Rice Farmer Household of Thailand
}

\author{
Jumpol Kullavanijaya \\ Regional Development Strategies Program \\ Surindra Rajabhat University \\ Email: jumpol.pea@hotmail.com
}

\section{Doi:10.5901/mjss.2013.v4n3p95}

\section{Abstract}

The research was qualitative approaches. The research design for qualitative research was In-Dept Interview with Ethnographic research technique of with 10 Thai peoples who live at Mekong River bank in Ubon Ratchani Province, the Northeastern region of Thailand. The content from qualitative research was analyzed to construct the questionnaire for quantitative research. Factor analysis was used for determination the component factors. The objectives of this research were 1) to study gender role related to energy supply and consumption in household and 2) to analyze content of gender role to construct items for factor analysis to identify the component of gender role related to energy supply and consumption in household. There were 6 components were constructed from 60 items. The 6 components were gender role involved energy supply and consumption, energy technology using in household at present and past, replacement with renewable energy, local wisdom energy technological use, energy technological use for health, and household energy conservation.

Keyords: Gender / Energy Technological Using / Rice Farmer Household /Thailand

\section{Introduction}

Energy from the sun has been used by people for centuries. During ancient time people have also used solar energy for drying, cooking, heating baths and warming their homes. Without electricity, mankind learned to orient their buildings to capture the heat of the sun during the day. Solar energy technologies include solar heating, solar photovoltaic, solar thermal electricity, solar architecture and artificial photosynthesis, which can make considerable contributions to solving some of the most urgent energy problems the world now faces (Royal Society of Chemistry, 2012; International Energy Agency, 2011).

In 2011, the International Energy Agency said that "the development of affordable, inexhaustible and clean solar energy technologies will have huge longer-term benefits. It will increase countries' energy security through reliance on an indigenous, inexhaustible and mostly import-independent resource, enhance sustainability, reduce pollution, lower the costs of mitigating climate change, and keep fossil fuel prices lower than otherwise. These advantages are global. Hence the additional costs of the incentives for early deployment should be considered learning investments; they must be wisely spent and need to be widely shared" (International Energy Agency, 2011).

Sun is the important source of energy. Particularly, the world receives the main energy from it. The plant uses the solar energy for photosynthesis to grow and to transfer energy to the other creatures continuously. Human consumes the plant as foods, clothes, drug and shelter. The fossil energy also has originated from solar energy for long time of accumulation of solar energy. It becomes crude petroleum before it distils to be oil or gasoline or diesel for various machine utilized whether for plane, car and other engine movement. With progress of science and technology development, the economic in terms of capitalism has widely opened for over consumption without regarding to the limitation of fossil energy supply (Thiengkamol, 2011e; International Energy Agency, 2011; Philibert, 2005).

Presently, human living has connected to energy consumption increasingly; therefore, it needs to develop innovation to serve the demand of daily living. The need of renewable energy emerges essentially for future. This kind of energy would be support for global citizen living (Thiengkamol, 2011e; International Energy Agency, 2011). It is obviously seen that all living creature depends on energy for sustainability, especially, solar energy.

Thailand, the electricity had been established in 1897 that was introduced by Field Marshal Chao Phraya Surasakdi Montri (Jerm Saeng-Chuto). Luang Pinitjakraphan and Mr. Leo Nadee (American) established a company named "The Bangkok Electric Light Syndicate" to generate electricity and sell to people under the operation of The Siam Electricity Co., Ltd., but the company could not gain benefit so they sold the company to Mr. Western Holz (Danish) to 
operate further. Afterward, Wat Lieb Power Plant was additionally established in 1898 and Sam Sen Electrical Power Plant was additionally established in 1912. It took responsible area dividedly since 1914. In 1910, His Majestry the King Chulachomklao royal command to announce using Act of Sanitation District across the kingdom R.S. 127 in 1929. The government set "Department of Electricity" for 25 years, then in 1932 there was revolution with bloodless to change the monarch regime to be democracy. The electrical trade was extended to other sanitation districts such as Prachin Buri, Phuket, Nakhon Nayok, Chon Buri, Ban phong, Chanthaburi, and Chiang Mai. Until 1935, there was improvement of ministry and department, therefore Department of Municipal Civil was established, therefore Electrical Division was raised to be Electrical Unit under Department of Municipal Civil (Electricity Generating Authority of Thailand: EGAT, 2013).

The National Economic and Social Development Plan 1, was implemented in 1961 when North Bangkok Power Plant was completely constructed and started its commercial operation, contributing to the end of power shortage in Bangkok Metropolis. The North Bangkok Power Plant was inaugurated by Field Marshal Sarit Thanarat and Lincoln B. Johnson then holding Thai Prime Minister and American Vice President respectively on May 17, 1961. Because of the rapid growth of electricity demand, Yanhee Electricity Authority (YEA) installed the second generating unit at North Bangkok Power Plant in 1962, and it firstly started its operation in 1963 (EGAT, 2013). The electrical supply in Middle region through Bangkok Metropolis as central of administration and business of Thailand is very importance for all sectors including household, governmental office and business.

However, for Northeastern region of Thailand, currently, the economic is extensively expanded because of ASEAN community is going to open in 2015. The ASEAN Economic Community (AEC) is the next step of economic integration transforming ASEAN into a single market and production base by 2015. The economic integration goals will include the elimination of tariffs, free professional movement, capital and a faster customs clearance procedure. Free Trade Area (FTAs) will be a key strategy for ASEAN to gain greater market access into trading partners and to attract foreign direct investments to ASEAN. AEC will increase regional economic prosperity and stability and reduce the development gaps among members (Mahidol University, 2013). Therefore, the Northeastern region of Thailand will play very important role as center of business for the AEAN countries such as Cambodia, Laos and Viet Nam.

At Present, the shortage of natural energy is caused by the over energy consumption of human, predominantly due to serving the life convenience of some group of people. Thailand also has faced this unavoidable crisis of energy shortage such as last summer in April, 2013, there are repairing the transported pipe gas in Republic of the Union of Myanmar and Malaysia (Boonviriya, 2013; EGAT International, 2013). Moreover, Thailand also impacted by natural disasters in various forms such as earthquake, flood, drought, and occurrence of new born vector disease and migration of living creature have constantly emerged due to climate change. Global temperature has increased on average by 0.2 degrees Celsius per decade over the past 30 years, and has caused unpredictable alterations to climate as well as more frequent and severe natural disasters such as earthquakes, landslides, volcanic eruptions, floods, storms, droughts, and forest fires. Ecosystems in many areas have become vulnerable and this has resulted in the loss of flora and fauna. The earth's surface has undergone physical changes, including coastal erosion and rising sea levels that have resulted in forced migration of coastal communities and damages to infrastructure, tourist areas, and coastal industrial zones where heavy investment has occurred. In addition, disease epidemics and outbreaks of insect pests have caused harm to human life, damage to agricultural products and threats world food security. Moreover, poverty, migration and fights over resources have occurred. The worldwide security of food and energy is under intense threat. Rising demand for food and energy is due to a significant increase in the world's population, whereas the supply of agricultural products has decreased due to limited arable lands, technology that has enabled crops to be used for energy rather than food, and climate change. This situation is likely to lead to increasing conflicts over food and energy in the future. Consequently, the supply of food in the world market could decline and bring about higher prices, especially in the poor countries. This would lead to a world food crisis (National Economic and Social Development Board Office of the Prime Minister, 2013).

Additionally, Thailand plan to reinforce natural resources as the foundation of the agricultural production base. Productive arable lands should be conserved and small farmers should be supported and assured of the right to own farmland. Land should be redistributed equitably, and tax policies should be used to increase the efficiency of land utilization. Further, land management mechanisms should be improved. Natural resources for agricultural production should be restored while good agricultural norms and practices should be promoted so as to support sustainable farming in order to solve the energy shortage at present and future (National Economic and Social Development Board Office of the Prime Minister, 2013). Therefore, it is a time that Thai peoples must turn their interests to study, search and consider the local wisdom of energy technological use in household level to investigate the cost and benefit balance to accomplish the effective economic and energy sustainability for sustainable development. 
People at both sides of the Great Mekong basin have culture of fire using for human living. They believed that when woman starts to be pregnant, her body will change and extend tremendously whether uterine, blood circulation, adornment skin, bone, blood vessel and hormone level will adjust to support germination. Lying by the fire after childbirth is a art and science of ancient people in Southeast Asian. The mother roasting and other practices of fire rest as they are called by midwife and acupuncturist Raven Lang pointed that it has numerous benefits because it reduces the uterine cramping that often after birth, promotes rest and relaxation and help to discharge excess fluid the accumulated during the pregnancy. Fire treatments were practiced throughout Southeast Asian including the Philippines, Malaysia, Sumatra, Sarawak, Thailand Vietnam and Borneo. Culture from Australia to Arizona also practiced mother-roasting technique (Romm, 2002). Mother roasting and other involved practices after childbirth can reasonably explain. Lying near the fire, taking a bath with warm water and drinking warm water will assist to increase body temperature to make a better blood circulation and heal the uterine cramping and returning to normal situation by reducing postpartum uterine bleeding and discharge. It also helps uterine mouth to close faster, therefore it prevents the infection of uterine and bleeding because local delivery is not sewing the vulva. Additionally, mother must take the salt to compensate the sweating during lying by the fire (Mhor Chao Bann, 2013).

The important cause of imbalance of global ecology is the trend of development and trend of living with aim to economic growth and progress or science and technology. These progress are accepted and admired by society but the way of life of rice farmers who are poor are looked down and taken advantage by others. The rice farmer in the Northeastern region has way of live with paying respect to the nature and living with mutualism. Therefore it leads to live with belief that human is a part of nature based on the Eastern belief (Chaithieng, 2006).

Gender involves energy use because women and men have different roles in the energy system and women bear the main burden of providing and using biomass energy for cooking. A situation made worse by fuel scarcity; and negative, health and safety impacts. Moreover, women bear the invisible burden of the human energy crisis, therefore they need modern and more efficient energy sources to improve their work and quality of life both within and outside the home. In society, women have less access than men to the credit, extension, land and training, necessary for improving energy access to support their livelihoods and income generation from micro-enterprises. Nevertheless, women and men have different kinds of knowledge and experience of energy, either through their traditional roles, their new non-traditional roles (especially in female-headed households), or increasingly as professionals in the energy sector. Since women experience poverty differently to men, they may need different energy policies to help them escape energy poverty: new energy technologies can even have unintended negative consequences for women, as has happened in the past with other new technologies e.g. in the Green Revolution (Energia, 2013).

From the mentioned reason, it is obviously seen that human has consumed hundred years, at present energy is going to be shortage soons therefore, numerous countries turn to pay attention to introduce the renewable energy for living such as plant energy and solar energy. It is interesting to study the gender role in energy technological use in household of Thai Northeastern Farmer to be guideline for developing the worth of energy technological using in household to be effective for living.

\section{Research Objective}

The objectives of this research were as the followings:

1. To study gender role related to energy supply and consumption in household.

2. To analyze content of gender role to construct items for factor analysis to identify the component of gender role related to energy supply and consumption in household.

\section{Methodology}

1. Qualitative research was used for data collection from In-Depth Interview form with 10 Thai peoples at Mekong River bank in Ubon Ratchani Province, the Northeastern region of Thailand.

2. The research design for qualitative research was In-Dept Interview with Ethnographic research technique of with 10 peoples (Chantarawanich, 1997; Thiengkamol, 2011a).

\section{Results}

\subsection{In-Depth Interview}


The results of In-Depth Interviews with 10 Thai peoples at bank of Mekong River in Ubon Ratchathani Province. It revealed that there were 6 components were constructed from 60 items. The 6 components were gender role involved energy supply and consumption, energy technology using in household at present and past, replacement with renewable energy, local wisdom energy technological use, energy technological use for health, and household energy conservation as illustrated in Table 1, 2, 3, 4, 5, and 6.

\subsubsection{Component 1: Gender role involved energy supply and consumption}

The details of each item obtained from content analysis of In-Dept Interview were presented as the following in table 1.

Table 1. Content Analysis Results of Component 1

\begin{tabular}{|c|l|}
\hline Items & Component 1: Gender role involved energy supply and consumption \\
\hline 1 & Woman has a main role for energy supply in household. \\
\hline 2 & Man has a main role for energy supply in household \\
\hline 3. & Woman consumes energy in household with economization concept. \\
\hline 4. & Man consumes energy in household without economization concept. \\
\hline 5. & Woman search energy for household supply from outside such as firewood and charcoal. \\
\hline 6. & $\begin{array}{l}\text { Man as husband house has main role to search energy for household supply from outside } \\
\text { such as firewood and charcoal. }\end{array}$ \\
\hline 7. & During lying near fire after childbirth, woman's mother takes care for this activity. \\
\hline 8. & Husband prepares the firewood for his wife during lying by the fire after childbirth. \\
\hline 9. & Woman suggests the household members to use energy with maximization. \\
\hline 10. & Man feels lesser concern to use energy with economization concept. \\
\hline
\end{tabular}

\subsubsection{Component 2: Energy technology using in household at present and past}

The details of each item obtained from content analysis of In-Dept Interview were presented as the following in table 2.

Table 2. Content Analysis Results of Component 2

\begin{tabular}{|c|l|}
\hline Items & Component 2: Energy technology using in household at present and past \\
\hline 1 & In the past the main energy for household is firewood from forest nearby village. \\
\hline 2 & In the past, man found the firewood for household energy. \\
\hline 3. & In the past, the majority of household used charcoal and firewood. \\
\hline 4. & In the past, the majority of household prepared charcoal by themselves. \\
\hline 5. & At present, the main household energy is electricity. \\
\hline 6. & At present, the main household energy for cooking is Liquefied Petroleum Gas (LPG). \\
\hline 7. & At present, the main household energy for cooking is firewood and charcoal. \\
\hline 8. & At present, the main energy for farming is manpower. \\
\hline 9. & At present, the main energy for farming is machine. \\
\hline 10. & At present, the main energy for farming is animal power. \\
\hline 11. & In the past, the main energy for farming is animal power and manpower. \\
\hline
\end{tabular}

\subsubsection{Component 3: Replacement with renewable energy}

The details of each item obtained from content analysis of In-Dept Interview were presented as the following in table 3.

Table 3. Content Analysis Results of Component 3

\begin{tabular}{|c|l|}
\hline Items & Component 3: Replacement with renewable energy \\
\hline 1 & The household member aware for energy shortage. \\
\hline 2 & Only woman is aware for energy shortage for household. \\
\hline 3. & Woman search cheaper energy for household supply. \\
\hline 4. & Household member uses Biodiesel as replacement for diesel. \\
\hline
\end{tabular}




\begin{tabular}{|c|l|}
\hline 5. & Household member uses Ethanol as replacement for Gasoline. \\
\hline 6. & Household member uses Natural Gas Vehicle (NGV) as replacement for Gasoline. \\
\hline 7. & Ethanol is a renewable fuel made from corn and other plant materials. \\
\hline 8. & Biodiesel is made from vegetable oils and animal fats with chemical reaction. \\
\hline 9. & The most popular energy for household is LPG for household cooking and car. \\
\hline
\end{tabular}

\subsubsection{Component 4: Local wisdom energy technological use}

The details of each item obtained from content analysis of In-Dept Interview were presented as the following in table 4.

Table 4. Content Analysis Results of Component 4

\begin{tabular}{|c|l|}
\hline Items & Component 4: Local wisdom energy technological use \\
\hline 1 & Household member realizes the important of solar energy. \\
\hline 2 & Household member uses solar energy for drying cloth by hanging under the sun. \\
\hline 3. & Charcoal production is old local wisdom. \\
\hline 4. & Firewood has been used for cooking and warming is local wisdom. \\
\hline 5. & Fire has been used for roasting food is local wisdom. \\
\hline 6. & Food preservation by drying under sun radiation is local wisdom. \\
\hline 7. & Meat drying under sun radiation is local wisdom for preservation. \\
\hline 8. & The quilt and blanket is hanging under sun radiation to killing the germ. \\
\hline
\end{tabular}

\subsubsection{Component 5: Energy technological use for health}

The details of each item obtained from content analysis of In-Dept Interview were presented as the following in table 5.

Table 5. Content Analysis Results of Component 5

\begin{tabular}{|c|l|}
\hline Items & Component 5: Energy technological use for health \\
\hline 1 & Lying near the fire after childbirth helps uterine mouth to close faster. \\
\hline 2 & Lying near the fire after childbirth is energy technological using for mother health. \\
\hline 3. & Mother roasting reduces the uterine cramping. \\
\hline 4. & Mother roasting helps to discharge excess fluid the accumulated during the pregnancy. \\
\hline 5. & Mother roasting assists to make body warmness. \\
\hline 6. & Mother roasting reduces the uterine pain and promotes rest and relaxation. \\
\hline 7. & Mother taken a bath with warm water helps better blood circulation. \\
\hline 8. & Mother drunk a warm water helps reduce postpartum uterine bleeding and discharge. \\
\hline
\end{tabular}

\subsubsection{Component 6: Household energy conservation}

The details of each item obtained from content analysis of In-Dept Interview were presented as the following in table 6 .

Table 6. Content Analysis Results of Component 6

\begin{tabular}{|c|l|}
\hline Items & Component 6: Household energy conservation \\
\hline 1 & Household member turns off the light. \\
\hline 2 & Household member unplugs electrical appliances. \\
\hline 3. & Only women concerns to turn off the light and unplugs electrical appliances. \\
\hline 4. & Household member uses the energy with consciousness of energy conservation. \\
\hline 5. & Only women concerns to expense of electrical consumption. \\
\hline 6. & Household member set air-condition at 25 degree Celsius. \\
\hline 7. & Mother teaches everyone in family to use with energy with economization concept. \\
\hline 8. & Household member unplugs the television after watching. \\
\hline 9. & Household member uses the remote to turn off television after watching. \\
\hline 10. & Household member realizes that the process of electrical power generation needs to use energy. \\
\hline
\end{tabular}




\begin{tabular}{|l|l|}
\hline 11. & Household member gathers the cloths to wash together before using watching machine. \\
\hline 12. & Household member gathers the more cloths to iron in the same time. \\
\hline 13. & Household member installs refrigerator at least 15 centimetres far from the wall. \\
\hline 14. & Household members watch the television together. \\
\hline
\end{tabular}

\section{Discussion}

It might be concluded that above study reflected to past and present of gender for energy technological using in rice farmer household of Thailand. In order to maximize the energy consumption in household, it requires collaboration among household members to conserve energy to accomplish sustainable development. Moreover, the household members should pay respect to mother because she is a people who take a burden of energy supply and conservation. Nevertheless, the new generation should reconsider to use the local wisdom of energy technological using that can help them to conserve energy and their household expense. Moreover, if every household realizes the important of energy technological using in terms of gender role involved energy supply and consumption, energy technology using in household at present and past, replacement with renewable energy, local wisdom energy technological use, energy technological use for health, and household energy conservation. This will lead to the real sustainable development by distributing this concept to other global citizen.

\section{References}

Boonviriya, S. (2013). Situation of Electricity. Report of Wastewater Unit, Department of Pollution.

Chaithieng, T. (2006). Project of Farmer Ecology; History, Culture and Wisdom of Farmer

Group at Mekong Basin. Kalasin: Kalasin Rajabhat University.

Chantarawanich, S. (1997). Qualitative Research. Bangkok: Chulalongkorn University Press.

EGAT. (2013). Thailand Electricity History. Retrieved from: http://www.egat.co.th/en/index.php?option=com_content\&view=article\&id $=11 \&$ ltemid $=152$

EGAT International. (2013). Poor People in Crisis of Electricity Shortage in Bangkok. Retrieved from: http://www.egati.co.th/index.php ?option=com_content\&view=category\&id=33\&ltemid=114\&|

ENERGIA. (2013). Why gender and energy? Retrieved from: http://www.energia.org/who-we-are/why-gender-energy/

International Energy Agency. (2011).Solar Energy Perspectives. Retrieved from OECD/IEA, 2011

Mahidol University.(2013).Towards ASEAN Economic Community in 2015.Retrieved from: http://www.cmmu.mahidol.ac.th/cmmu lindex.php/asean-community-2015

Mhor Chao Bann. (2013).Lying by the Fire after Childbirth. Retrieved from: http://www.doctor.or.th/article/detail/3703

National Economic and Social Development Board Office of the Prime Minister. (2013). The Eleventh National Economic and Social Development Plan (2012-2016). Retrieved from: http://www.nesdb.go.th/Portals/0/news/plan/p11/Plan11_eng.pdf

Philibert, C.(2005). .The Present and Future use of Solar Thermal Energy as a Primary Source of Energy. France: OECD/International Energy Agency.

Romm, A. (2002). Natural Health After Birth : A Complete Guide for Postpartum Wellness. Vermont: Healing Art Press.

Royal Society of Chemistry.(2012).Solar Fuels and Artificial Photosynthesis. Retrieved from http://www.rsc.org/ScienceAndTechnology /Policy/Documents/solar-fuels.asp

Thiengkamol, N. (2011a). Holistically Integrative Research. 2nd Edition. Bangkok: Chulalongkorn University Press. 